Erratum

\title{
Erratum to "Skeletal Muscle Mass Indices in Healthy Young Mexican Adults Aged 20-40 Years: Implications for Diagnoses of Sarcopenia in the Elderly Population"
}

\author{
H. Alemán-Mateo and Roxana E. Ruiz Valenzuela \\ Coordinación de Nutrición, Centro de Investigación en Alimentación y Desarrollo (CIAD), A.C. Carretera a La Victoria Km. 0.6, \\ 83304 Hermosillo, SON, Mexico \\ Correspondence should be addressed to H. Alemán-Mateo; helio@ciad.mx
}

Received 13 May 2014; Accepted 12 October 2014; Published 4 November 2014

Copyright (c) 2014 H. Alemán-Mateo and R. E. Ruiz Valenzuela. This is an open access article distributed under the Creative Commons Attribution License, which permits unrestricted use, distribution, and reproduction in any medium, provided the original work is properly cited.

In the paper entitled "Skeletal muscle mass indices in healthy young Mexican adults aged 20-40 years: implications for diagnoses of sarcopenia in the elderly population" there was a wrong citation in Table 3. First, the correct last name is Masanes et al., 2012 [13]. Second, we want to correct in our published work the sex-specific cut-off points reported by Wen et al., 2011 [9], and Kim et al., 2009 [10] (Table 3). The correct values are 5.85 and 4.23 for men and women, respectively, in the case of cut-off points published by Wen et al., 2011, and 5.14 for women, in the case of Kim et al., 2009. Finally, we want to clarify that these small changes do not affect the results of the statistical analysis reported in our published work. 


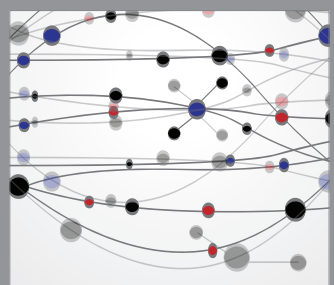

The Scientific World Journal
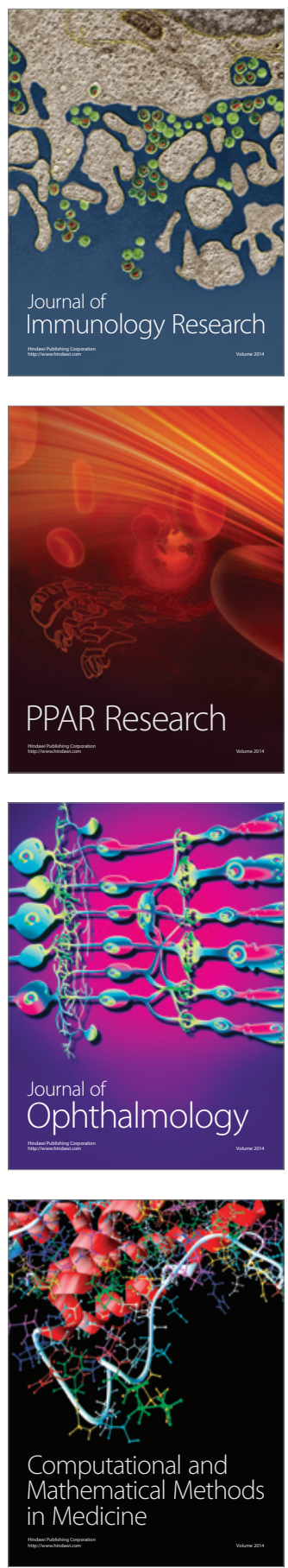

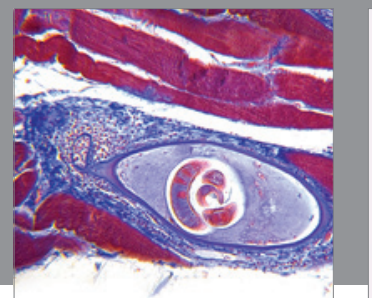

Gastroenterology

Research and Practice
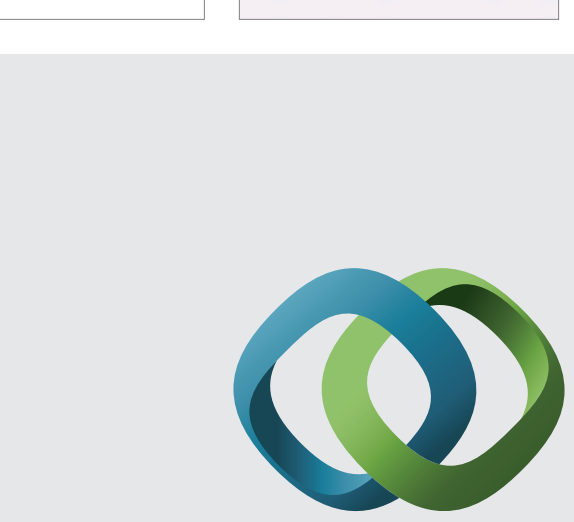

\section{Hindawi}

Submit your manuscripts at

http://www.hindawi.com
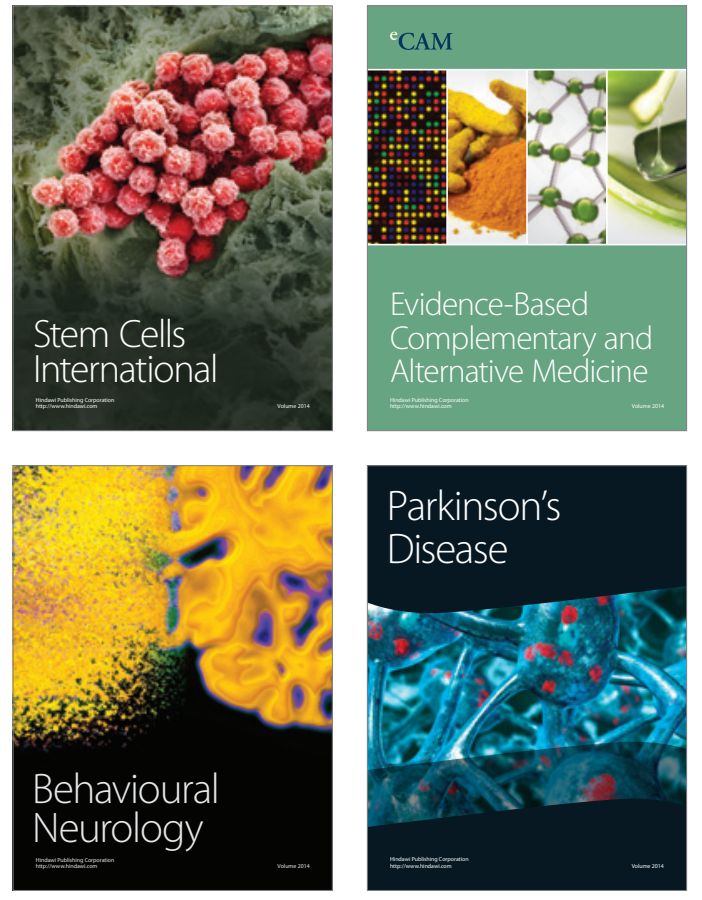
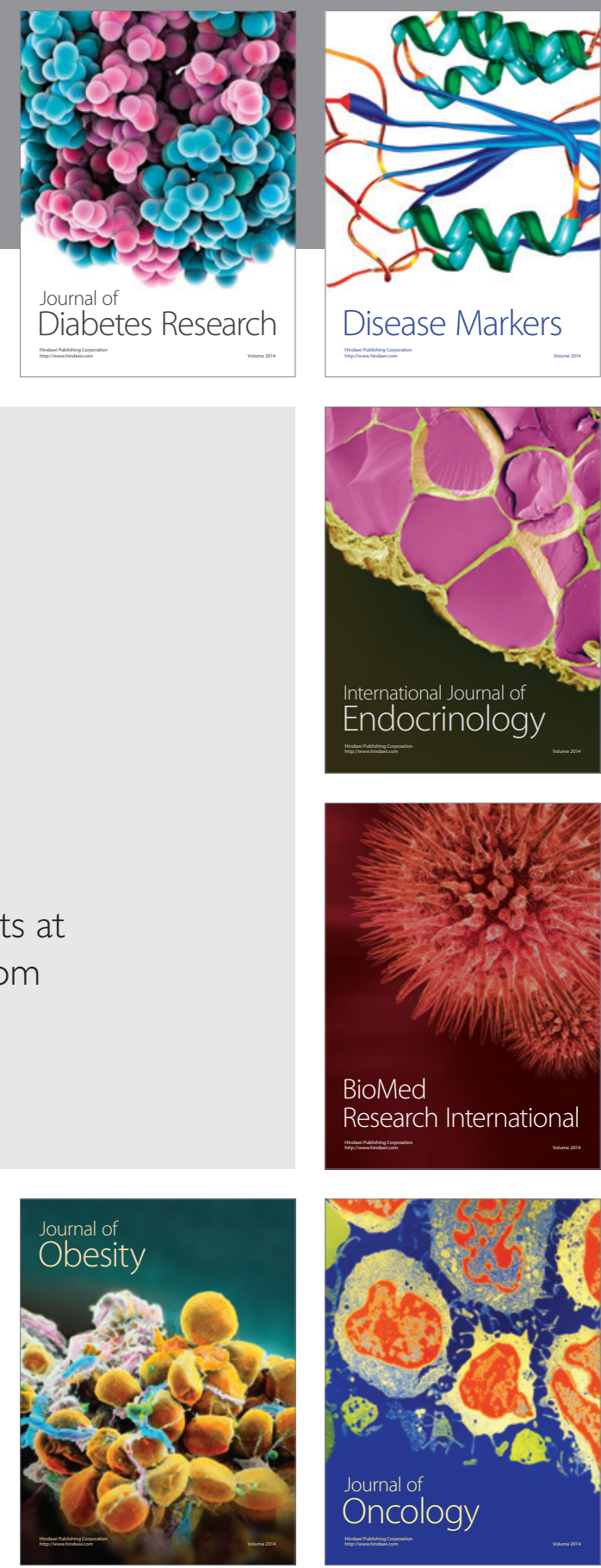

Disease Markers
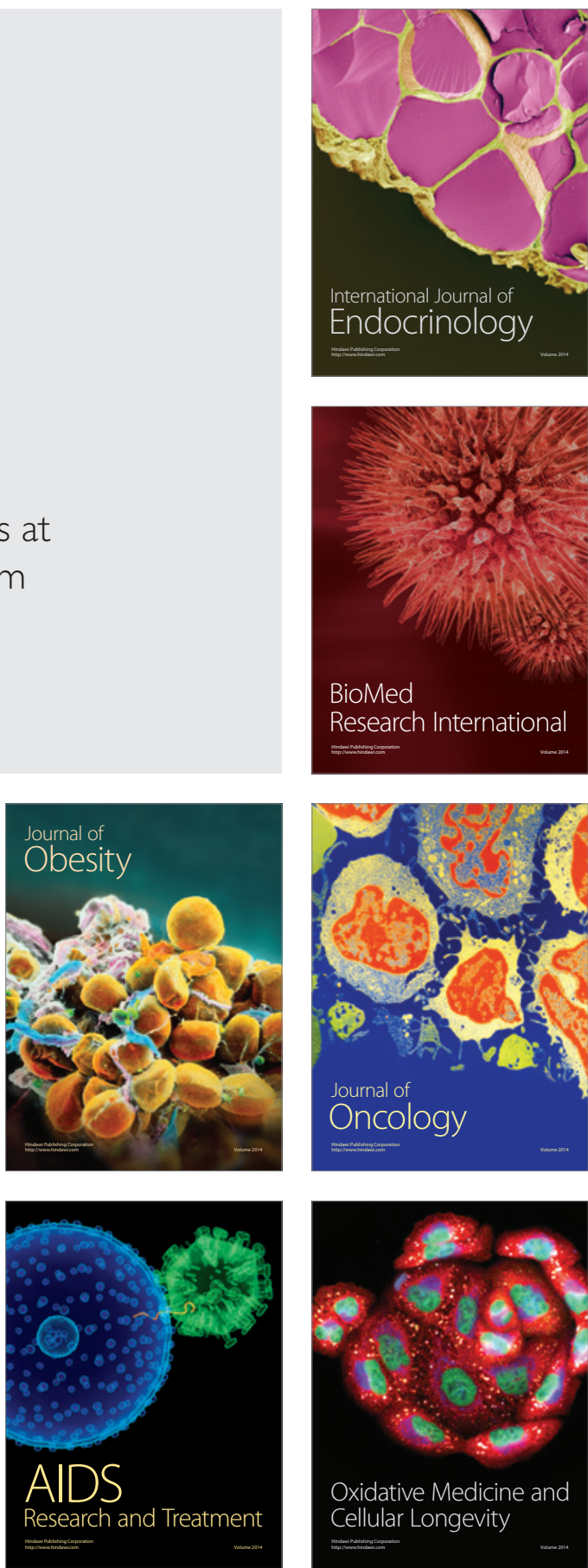